\title{
REALLEXIKON \\ DER VORGESCHICHTE
}

ZWEITER BAND 
Copyright 1925 by Walter de Gruyter \& Co., Berlin 


\title{
REALLEXIKON
}

\section{DER VORGESCHICHTE}

\author{
UNTER MITWIRKUNG \\ ZAHLREICHER FACHGELEHRTER \\ HERAUSGEGEBEN VON \\ MAX EBERT \\ ORD PROFESSOR AN DER UNIVERSITÃT KONICSBERG
}

\section{ZWEITER BAND}

ERSTE LIEFERUNG

BESCHWÖRUNG -- BÖHMEN-MÄHREN

MIT 4 TAFELN

\author{
BERLIN 1925 \\ WALTER DE GRUYTER \& CO.
}


Das Werk erscheint in Lieferungen mit zahlreichen Tafeln und Textabbildungen. - Der Subskriptionspreis beträgt GM. 6.- für jede Lieferung von etwa 8 Bogen nebst Texttafeln und Abbildungen. Ca. 6-8 Einschalttafeln auf Kunstdruckpapier werden als ein Bogen gerechnet. Verstärkte Lieferungen werden entsprechend höher berechnet. Der Subskriptionspreis erlischt am 1. April 1925. Er gilt dann nur noch für Abonnenten, die bis zu jenem Termin subskribiert haben. Das ganze Werk ist auf ca. 250 Bogen Lexikon $8^{\circ}$ berechnet und wird in mehrere Bände geteilt. 